\title{
Nomadismo e liberdade
}

\section{JACQUES ATTALI}

$\mathrm{M}$

il quatrocentos e noventa e dois é considerado como data importante não apenas por marcar a descoberta fortuita de um nopo mundo enquanto se procurava outra coisa, mas também por condicionar e esclarecer o presente.

Esse mesmo ano é o resultado - o filho? - de um longo período de gestaçáo, durante o qual a Europa se liberta das influências externas, desperta para o comércio e a inovação, forja sua própria visão da história e da geografia, colocando-se no centro do mundo; é também o ano em que começam a ser definidas as consequiências práticas, e freqüentemente desastrosas, dessa visão. É o ano no qual a Europa se torna o que denominamos um Continente-História, capaz de impor aos demais povos um nome, uma língua, uma maneira de contar sua própria História, impondo-lhes ideologia e visão do futuro.

Naturalmente, 1492 não significa idéia de ruptura, mas apenas ponto de chegada, momento em que o gigante acorrentado quebra seus elos. Durante vários séculos a geografia cristá na Europa esquece a intuição dos gregos sobre a redondidade da terra, negligencia o saber judaico-muçulmano e esquece as descobertas ocidentais dos vikings. $O$ planeta é representado como um disco achatado, tendo em seu centro primeiro Jerusalém, depois a Europa e, mais ao longe, uma terra tórrida povoada de cinocéfalos; circundando-o, um anel aquático. Essa percepção continuará por muito tempo como a visão dos europeus, que se colocam no centro do universo mesmo depois que as mutaçóes científicas os levaram a redescobrir a redondidade da Terra.

Há cinqüenta anos Constantinopla caiu, e com ela Atenas. O mundo grego, despedaçado, aflui com seus manuscritos para Florença, onde Lourenço de Médicis financia as pesquisas filosóficas do genial Marcile Ficin. Conscientes desde 1380 da ameaça turca, os europeus portugueses e castelhanos ainda mais que outros - lançam-se à procura de nova rota marítima para o Oriente, contornando a África, passando depois pelo outro lado. Chocam-se com a nova terra que, de certa maneira, os constrangerá até integrarem-se em visão global e coerente do mundo.

A partir de 1492, a Europa promove-se a senhora de um mundo 
a ser conquistado, o que chamarei mais adiante, de uma Ordem Atlântica.

Novos nômades, os europeus impóem ao planeta sua visáo de História, sua criatividade, suas línguas, seus sonhos e suas fantasias. É na Europa que a economia mundial vai concentrar suas riquezas.

Tudo isso não ocorre apenas pelo desvendamento de um continente. Em 1492 acontecem inúmeros outros eventos, na Europa e em outros lugares, cuja influência sobre a nova ordem mundial ultrapassa de longe a da viagem de Colombo. Acontecimentos maiores ou apenas simbólicos formam uma totalidade complexa, um ano quase único, no qual a Espanha desempenha papel espantosamente privilegiado. Cai o último reino islâmico da Europa ocidental; os últimos judeus sáo expulsos da Espanha; a Bretanha acaba por tornar-se francesa; a Borgonha desaparece para sempre; a Inglaterra sai de uma guerra civil. Em Nuremberg, Martin Behaïm constrói o primeiro globo terrestre; em Roma, debate-se a idéia da primeira transfusão de sangue e, pode-se dizer, até se ensaia fazê-la na pessoa do papa; em Salamanca, o professor Nebrijá publica a primeira gramática em língua vulgar, marcando o fim do domínio do latim; em Ferrara, representa-se a primeira peça de teatro, no sentido moderno do termo; em Roma, um Borgia se elege como papa; em Florença, morrem Lourenço de Médicis e Piero della Francesca, encerrando a primeira fase do Renascimento; Dürer realiza o primeiro auto-retrato da história da pintura e Da Vinci trabalha na Gioconda; Erasmo é ordenado padre.

A ordem econômica mundial transforma-se. A China fecha-se e se apaga; a Índia continua fragmentada em múltiplos reinos; na África, Ali Ber - rei dos songais - impóe-se contra o império de Mali; na Europa ocidental, Veneza enfraquece como centro da vida econômica curopéia, pois a Turquia fecha as rotas das galeras para a Índia, por terra ou por Alexandria; na Itália, cria-se o primeiro sistema monetário internacional; a Inglaterra renuncia às suas ambiçóes continentais pelo tratado de Etaples; e toda a Europa ocidental, dando as costas ao Leste, olha agora para o Atlântico, por onde os europeus logo farão vir o tabaco, o cacau, o milho e a batata, além da sífilis, pela qual sua sexualidade é transtornada. Conter-se, poupar, torna-se a palavra de ordem que substitui a liberdade precedente, estruturando a moral econômica e sexual por séculos.

Ninguém sabe ainda qual cidade, entre Gênova, Cádiz, Lisboa ou Anvers, tornar-se-á o novo coração da economia. A ideologia do mundo novo está assentada. 
Isso quanto aos fatos. Mas como julgá-los hoje? O que se descobriu em 1492? Em outras palavras, quais as conseqüências desse acontecimento? Vou citar três. Três características da ordem política dos séculos vindouros. Uma no domínio da transcendência; outra no do espaço; e a terceira, no do tempo: a Pureza, o Estado-Naf̧ão e o Progresso que, juntos, formam o que eu chamarei de Ordem Atlantica.

Pureza, primeiramente, é a dimensáo de transcendência. Em sua obsessáo de identidade, a Europa de 1492 quer ser pura de qualquer influência externa. Inventa para si um passado (fé sem o judaísmo e o Islā), organiza um presente (moral contra a sífilis), constrói um futuro (a conquista do Novo Mundo). Trata-se de fundar um Paraíso Perdido, uma ordem sem parasita, uma utopia sem imperfeiçáo. Toda ordem religiosa ou política define-se pela exclusáo do outro - bode expiatório: aqui o nômade, o judeu, o não-cristáo, o impuro. É claro que esse descjo de expulsão, de extermínio, de eliminação do outro é muito mais violento porque o inimigo, o impuro, o bode expiatório - o judeu, o muçulmano, o pobre, o nômade, em geral - seduz o exterminador, visto que é parte integrante de sua identidade rejeitada.

Forjar o Homem novo, inventar para si um pai e dar-se um filho puro e perfeito, construir um mundo livre de qualquer passado, é agora o maior objetivo das novas potências da Europa. Um homem puro, sem qualquer mancha, lavado do pecado original.

Essa Europa que, entretanto, fundou sua primeira identidade sob o fascínio do Oriente, onde havia nascido, nega agora tudo o que the deve. Esquecendo seu passado oriental, sua cultura mediterrânea e seu componente islâmico, perdendo sua tolerância, sonha agora em ser romana e não hierosolimita; vê s̀eu centro cultural em Florença e não em Atenas.

Assim, tanto o judeu como o muçulmano perderam seu lugar, particularmente na Espanha. O judeu é o passado, aquele que, apenas por sua presença, lembra Deus ser babilônio, e depois palestino, antes de ser romano e mais tarde espanhol. No fundo, não se teme o judeu, mas duvida-se da fragilidade da convicção cristã, da qual o judeu, e mais tarde o muçulmano, é o revelador, porque pode reconverter o convertido.

A Igreja, enfraquecida pela eleição de um Borgia no Vaticano e pelos múltiplos cismas que se anunciam, sente-se insegura quanto a tolerar qualquer inimigo, por menor que seja. Assim, nesse ano, a expulsáo dos judeus da Espanha - o gueroush, que significa em hebraico tanto divórcio como expulsão, marcando a felicidade de ser cspanhol - é como 
uma medida preventiva face à ameaça que só vai ser concretizada de fato mais tarde, no próprio âmago da Igreja: a ameaça daqueles que não aceitam ser a Cristandade, antes de tudo, uma potência política, emanação da Europa; daqueles que desejam tornar-se ela portadora de mensagem universal, vinda do Oriente. De certo modo, a eleição de um Borgia para papa, em agosto de 1492, abre caminho para a reforma.

Fracassada na Europa essa busca de pureza, o índio, descoberto desvendado - além-Atlântico, representa o material para construir o homem ideal, puro de qualquer mácula; melhor ainda que qualquer europeu, na medida que não conhece as raízes orientais da fé européia. A expectativa dos senhores da Ordem é de resgatarem-se da própria impureza, de suas próprias fontes, edificando o Cristáo perfeito sobre as ruínas de outras civilizaçóes. Para eles, a amnésia é pureza. O massacre é redentor. Velhas histórias que seriam encontradas entre os jesuítas do Paraguai.

Certamente, essas civilizaçóes não servem como modelos de direitos humanos. Em dois casos, pelo menos, chegam a ser abomináveis ditaduras canibais. Mas nada justifica a morte de sessenta milhóes de pessoas em nome dessa Nova Ordem, ou seja, o equivalente à populaçáo européia da época.

O mesmo sonho de pureza, essa transcendência pela designação do sujo, ressurgirá várias vezes na Europa. Para falar apenas do século $\mathrm{XX}$, tal sonho é encontrado na Alemanha nazista e na Rússia stalinista, suscitando genocídios e massacres de classe: o nazismo encontra sua fonte nas reflexóes sobre a pureza do sangue dos teólogos espanhóis do fim do século XV, que conclui a reflexão sobre a expulsão dos judeus com recusa da própria conversão; o comunismo, também visando ao advento de um Homem novo, livre de impurezas - as do capitalismo. O fracasso desses paraísos perdidos é uma lição que não pode ser esquecida. Hoje, na Iugoslávia a purificação étnica é a palavra de ordem explícita, como o foi na Turquia e, de modo totalmente diferente, no Camboja.

O sonho de pureza permanece um ideal inatingido, adormecido em todo homem e ameaçador em cada sociedade. A meu ver, é o melhor do Homem e o pior para o Homem; o melhor quando o leva a superar-se, o pior quando se encarna em um sonho coletivo, o da Naçáo.

O conceito de Estado-Nação, surgido também em 1492, submergirá a Europa durante cinco séculos. Quando se desvanecem os sonhos de unidade federal européia, sob a égide do papa ou do imperador, emergem os Estados-Naçốs. Transcendendo os povos que a constituem, 
a nação torna-se um ideal de unidade, mistura racional de leis e de culturas comuns em determinado território. Somente considerada civilização quando nega a pureza étnica e designa como impuro apenas o mendigo e o nômade; quando designa como povo "a universalidade dos habitantes do reino", como fazia Sébastien Pot, o Chanceler borgonhês que se tornou alto funcionário do rei Carlos VII, nos Estados Gerais de Tours.

Os impérios desaparecem. Instalam-se fronteiras mais nítidas e melhor guardadas. Naçōes organizam-se em torno de monarcas e burguesias. O Estado, desde então, dá à nação - mosaico de povos - a estrutura, a justificação, a identidade necessárias. Não há nação sem Estado. Nesse momento, aparecem a razâo de Estado e o bomem politico moderno, assim como o cálculo econômico e o mercado. A democracia e a economia de mercado seráo elementos constitutivos desse nacionalismo nascente. Quando as naçóes se estruturam em torno de uma burguesia que se instala, surgem esses dois valores, como aqueles que a estruturam e reforçam.

Desde 1492, esses dois valores ligam-se e alimentam-se reciprocamente.

Primeiro aparece o mercado, exigindo a liberdade de circulaçáo das pessoas, dos bens e da informação, o que demanda a democracia. A democracia, por sua vez, exige o direito de empreender, que apenas o mercado autoriza. Com o mercador e o aventureiro, com o jurista e o político, a economia de mercado e a democracia nascem na nação européia do fim do século XV. Ambas estruturam as Naçôes da Europa. Sua monarquia absoluta não resistirá.

A terceira característica, conseqüência ainda dos acontecimentos de 1492, é o progresso. Antes, tudo era cíclico; o mundo acabado movia-se, num equilíbrio intransponível. Depois, com o aumento das dimensóes do mundo, de sua populaçáo e de sua produçáo, com o desenvolvimento da imprensa e surgimento dos livros, é criado um um sentimento de desequilíbrio, de perpétua marcha para a frente em único sentido: o do melhor. O mundo de camponeses apavorados torna-se o dos nômades em busca de um ideal, sempre alerta; a vigilância deixa de ser obstáculo e torna-se virtude. Os livros, e depois as gramáticas impressas, fazem explodir a cultura latina, substituída por culturas nacionais. Tecnologias aceitas pelo poder constituído - porque ele se considera instrumento de centralização - criam a diversidade para nações diversas e o desmoronamento de impérios. Ocorrências que não podem ser esquecidas. 
A expulsáo dos judeus da Espanha acelera essa excepcional revoluçáo mental e o progresso do saber. Constrangidos a converterem-se ou partir, aqueles dentre os grandes intelectuais que decidem permanecer são condenados, pelo menos durante duas geraçóes - até o seu exílio final - ao jogo duplo, à ambigüidade; a vida de incertezas e clandestinidade moral aguça seu espírito crítico, a ponto de fazê-los pensar livremente, sem referência aos dogmas que os solicitam. Marranos - ou de ascendência marrana -, Encina, Montaigne e Spinoza, alimentados pela ambigüidade e pela dúvida, vivem na duplicidade; apreciam, depois admitem, coisas contraditórias, recusando doutrinas absolutas, as certezas. $O$ intelectual moderno, para quem a descoberta encontra-se na dúvida e o desvendamento é encontro de novo mistério, nasce desse pensamento de resistência, desse homem de resistência, desse duplo com certezas múltiplas. De Cervantes a Freud, de Shakespeare a Einstein - por que não a Woody Allen? - , todos mestres nessa arte da ambigüidade, vai-se encontrar a mesma filiação do intelectual e a mesma tragédia de sua relação com o poder.

Falei de um senso do transcendente (a pureza); um senso do espaço (o Estado-Nação); um senso do tempo (o progresso).

Em suma, 1492 leva também à reflexão sobre uma Ordem Atlantica: a Europa das Naçóes dirige a economia de mercado e a democracia do Ocidente. Ela se apropria do Atlântico, explorando os recursos da América em proveito próprio, para construir o sonhado paraíso de pureza. Colonizará a África e a Ásia. A Ordem Atlântica é um mundo cristão. A Europa Ocidental mutila-se de seu Oriente, fecha-se a essa parte de si mesma onde novos impérios se estruturam. Após a morte de Casimiro IV, rei da Polônia, o Leste do continente dedica-se ao despotismo e aos impérios.

Durante cinco séculos o Atlântico dominará o mundo, contra um Oriente obscuro e hostil. Uma fronteira é traçada nos confins dos impérios russo e otomano. A Ordem Atlântica detém-se nessas fronteiras. As potências coloniais perecem, umas após outras, sob o peso de suas vítimas.

É preciso não esquecer as próprias fronteiras. A Ordem Atlântica é construída contra Leste e Sul, entre Leste e Oeste. Fronteiras são definidas em 1492, ou pouco depois, com o Tratado de Tordesilhas. A Guerra Fria é o último avatar desse antagonismo entre Ordem Atlântica e impérios da Europa Oriental. A Comunidade Européia estabeleceu-se com as bênçáos americanas, como muralha contra o comunismo e, ao mesmo tempo, modo de sepultar o nacionalismo alemão e a colaboraçáo 
francesa. Com ela, 1492 apaga-se, de certa forma, pclo retorno do sonho de unidade da Europa, mais ainda dentro da Ordem Atlântica, tendo sempre o mesmo inimigo impuro.

Esse muro, bem no coração europeu, serviu também para a defesa da Europa Ocidental contra a Ásia, como explica o historiador Fernand Braudel; em suma, a paz do Ocidente, desde 1492, fundamenta-se na infelicidade do Leste. Em 1987, Vaclav Havel o dirá com as mesmas palavras: "A felicidade do Ocidente seria bem ambígua, se seu corolário permanente devesse ser as infelicidades do Leste".

Essa é a Ordem Atlântica, que termina em 1989, sem que se perceba, ao derrubar-se o muro, e descobrir-se que as duas partes da Europa são porçốes de um mesmo continente, participando da mesma geografia, da mesma história; em outras palavras, a Europa redescobre-se na parte oriental, ortodoxa e muçulmana.

Reflitamos um instante sobre essa questão tão importante, pois até aqui foram assimilados Europa e Ocidente. A realidade, após a queda do muro, é muito mais complexa e nos remete à Europa anterior a 1492.

Onde começa e onde acaba a Europa? Vai do Atlântico aos Urais? É definida por limites étnicos? Culturais? Religiosos? É um clube cristáo? E, se vai do Atlântico aos Urais, de qual lado do Atlântico?

Na minha opinião, há necessidade de reflexão antes de excluir a América do futuro da Europa. Estados Unidos e Canadá, México e Brasil constituíram-se através de virtudes duvidosas dos massacres e do nomadismo posteriores a 1492, como naçóes européias, mais que qualquer dos países do continente. Encontram-se em Nova Iorque, Chicago e Vancouver, mesmo em Buenos Aires ou México, muito mais nacionalidades européias miscigenadas que em Paris, Madri ou Londres; e nesses locais, línguas européias são as faladas. É uma Europa miscigenada e não justaposta à encontrada na América, tanto no Norte como no Sul.

Até os Urais? A resposta, em 1492, era afirmativa, pois os limites da Europa eram os da cristandade; fixavam-se onde começava a guerra contra os não-cristáos pela reconquista, sempre adiada, de Jerusalém. E nos Bálcãs, onde se situa o limite? A Europa Meridional, na Iugoslávia, termina onde termina a cristandade? Era assim, em 1492. Convém não incorrer no mesmo erro. Procedendo dessa forma, Bósnia, Albânia, parte da Bulgária e Turquia não estão na Europa. É exatamente o que acontece hoje em Sarajevo e amanhã em Kosovo, na Macedônia, entre 
outros lugares. Questôes que não podem mais permanecer camufladas e marcarão, amanhã, os debates sobre o futuro da Comunidade Européia.

Para além dos Urais, ainda é Europa? Se a Rússia é um país europeu, o é até Vladivostok? O que acontece com repúblicas como Armênia e Geórgia? Azerbaidjão e Turquestão? Enfim, o que são Maghreb e Oriente Médio, locais onde vivem todos os povos que fundaram a cultura européia? Questóes insolúveis. Em minha opinião, a Europa é um lugar de memória, com fronteiras fluidas e que deve se redescobrir pluricultural, até às fronteiras incertas com a Ásia e com a África.

Sejam quais forem suas fronteiras, a Europa deve agora ser repensada, ao mesmo tempo em que é transformada a Ordem Atlântica de quem foi mãe, e de cuja filha, na América, foi a última mestra.

O fim da guerra fria marca - com o fim dos impérios - o desaparecimento do inimigo que definia a identidade da ordem, canalizando a violência para um bode expiatório: agora, cada qual tem o mesmo sonho, e essa identidade é geradora de violência.

E não há possibilidade de ajudá-los a construir, a financiar reconstruçăo e desenvolvimento, a admitirem-se como europeus sem serem, por essa razão, massacrados pelos descobridores.

Entretanto, para obter sucesso no que falhou em 1492, a Ordem Atlântica não deve apresentar-se como conquistadora: não é o caso de tratar os europeus do Leste como os indígenas da América foram tratados pelos espanhóis do século XVI e pelos ingleses do século XIX, ou como os franceses e outros trataram os africanos. Os países ocidentais devem reconhecer, no diálogo com o Leste, não serem seus modelos os melhores produtos de exportaçäo; que a pureza provoca a barbárie; 0 nacionalismo é fonte de violência; o mercado, na ausência de instituiçóes, é apenas um mercado negro; e a democracia sem regras é a anarquia. Os países ocidentais devem aprender primeiramente a praticar entre si o que preconizam aos outros, sobretudo quanto à proteçáo social, abrindo suas fronteiras a pessoas, idéias e produtos daqueles que se extenuam ao aplicar as reformas draconianas a eles recomendadas com tanta insistência. Em resumo, como em 1492, está ocorrendo uma reviravolta, que exigirá transformaçóes tanto do descobridor como do descoberto.

Os ocidentais não devem ver nos princípios da Ordem Atlântica (Pureza, Nação, Progresso) os elementos fundadores de um Homem novo em um novo paraíso. Se assim fosse, levariam apenas à criaçáo de uma gigantesca economia de mercado negro, sem Estado de direito e mafiosa na metade oriental da Europa. Isso nāo interessa a ninguém. 
A redescoberta da Europa Oriental transforma a ordem mundial: esta não pode mais ser Atlântica; é planetária e a Europa não está mais em seu centro, desde que novamente se centra em si mesma.

Surge nova ordem mundial, fundada sobre três novos princípios, os quais substituem os da Ordem Atlântica: na transcendência, santudrio mundial (em lugar de pureza), no espaço, integrafẵo regional (em vez de Estado-Nação), e no tempo, nomadismo institucional (substituindo progresso).

Permito-me discorrer rapidamente sobre esses princípios: em primeiro lugar, o Santuário. Atualmente, todos reconhecem que a Ordem Atlântica ameaça, por seus próprios princípios, o que é próprio do homem. Todos os valores da Ordem Atlântica exaltam o efêmero como valor, como critério do sucesso e do poder. Os três princípios que a caracterizam (pureza, progresso e naçăo) são destruidores, fazendo apologia do fugaz. Hoje assimilam-se pureza e juventude, que é efêmera. O progresso exige mudanças como a democracia; e a economia de mercado também a exige; mudam-se políticos e dirigentes pelo voto; mudam-se produtos pela compra. Produtos, como políticos, sáo cada vez mais efêmeros, mutáveis, nada durável está protegido. Seu valor é a sua popularidade. Deseja-se o que é vendido. O lugar ocupado no bit parade determina o valor de um político, de uma estrela, de um automóvel: se existe a qualidade é porque a maioria pensa assim. E reina o efêmero. $O$ canibalismo industrial substitui o teológico, das sociedades pré-colombianas.

Os bens mais preciosos para a vida humana como o ar que se respira, a água e as florestas, o código genético estão ameaçados. É preciso protegê-los das mudanças, para inscrevê-los num santuário. Uma transcendência. $O$ código genético faz parte desse santuário. Náo deve ser campo de conquista para um novo Colombo.

Para tanto, é preciso que instituições internacionais estejam capacitadas a tratar desses problemas e a reconciliar as diferenças de modo pacífico e democrático, a longo prazo. Ainda se está longe de tal procedimento: a reflexăo sobre o que é próprio do Homem, sobre o que é suficientemente essencial e deve ser protegido da degradaçáo irreversível. Esse santuário, livre de qualquer parasita, de qualquer ruído, também se refere ao patrimônio, às línguas, aos costumes. Como deter sua destruiçăo sem ditadura?

O segundo valor refere-se à integração regional. $O$ mercado atual é cada vez mais supranacional. Nascido no Estado-Naçáo e na democracia, exige ampliação das bases e negação das fronteiras. Em diversas 
partes do mundo, em razão dessa mudança, uma integração regional está em marcha; é o caso, entre outros, da Comunidade Européia, da Zona Norte-Americana de Livre Comércio e do Conselho da Bacia do Pacífico. A economia exige essa ampliação. Deve ser democrática, em caso contrário será inaceitável; e, para isso, é preciso uma democracia sem fronteiras ou, pelo menos, de fronteiras mais extensas. Ora democracia e economia de mercado se contradizem; ora a prática da democracia nacional precisa de fronteiras nacionais para definir sua jurisdição e estabelecer os direitos de cidadania.

A integração econômica não deve ser refreada. Na Europa, o mercado pode ser um meio formidável para ajudar a manutenção da paz. No momento em que a parte ocidental do Velho Continente se questiona sobre maior integração política, surge o nacionalismo, ameaçando por toda parte. Se o deixarem florescer, se novas fronteiras se erguerem no Leste, como no Ocidente, serão prenúncio de xenofobia, como o risco representado por $\mathbf{3 0 . 0 0 0}$ ogivas nucleares sempre prontas a serem ativadas. $O$ mercado pode ajudar as fronteiras a perderem parte de sua significação, a facilitar a aceitação do nomadismo e do movimento, evitando o ciclo de divisáo dos impérios e etnias cada vez mais puros e entrincheirados. Isso, caso se saiba como impedi-lo de reduzir demasiadamente tais diferenças.

A Europa tem uma única alternativa: a integração continental ou o esfacelamento nacionalista. Em cinco séculos, este último provocou incontáveis barbáries. É por isso que prego a criação de um Mercado Comum continental, o qual reuniria a CEE e todos os outros países do continente $\mathrm{em}$ um acordo de livre circulação de pessoas e idéias. Aposto que tal procedimento não será fator de uniformidade, mas, contrariando a mestiçagem que acarreta, produzirá novas diferenças, mais ricas que as precedentes.

Essa integração não causará, como receiam alguns, perda de identidade Ao contrário: quanto mais forte é a identidade, melhor se defendem seus interesses em um nível ampliado. As movimentaçóes nacionalistas que hoje se insurgem contra a integração regional, na verdade, são apenas a manifestaçáo de identidades frágeis daqueles que se inquietam.

Mas a liberdade de circulação é, antes de tudo, a dos homens. Retorno do nomadismo. Ela é possível, em um planeta cada vez mais superpovoado? Pode-se aceitar o movimento de dezenas de milhóes de pessoas, único capaz de assegurar a liberdade de ir para onde o clima e o nível de vida são considerados agradáveis? Ou veremos os homens enclausurados, presos, constrangidos? 
Na minha opinião, isso nos leva ao terceiro elemento da nova ordem mundial: o nomadismo institucionalizado, que ultrapassa a idéia de progresso, nascida em 1492. Yehudi Menuhin disse, certa vez, que a Europa será a Europa quando um cigano puder nela viver onde bem entender. Isso é mais verdadeiro do que nunca, e não apenas na Europa. A Ordem Atlântica era a dos sedentários. Estamos cada vez mais cercados por objetos portáteis, utensílios de um nomadismo high-tech. Há os nômades ricos do Norte e os nômades miseráveis do Sul. Uns representam a ordem; os outros a desordem. E o Sul é no Norte. O Sul é feito de nômades constrangidos, enquanto o Norte é feito de nômades voluntários. É preciso preparar um futuro no qual o tempo não será mais unidimensional; no qual todos os seres humanos, nômades potenciais, deverão compartilhar um universo multiforme, podendo exercer sua cidadania em diversos momentos em diferentes lugares e ter regalias múltiplas; um futuro no qual o fato de pertencer a uma comunidade não se chocará com o dever em relação a outra e não a ameaçará em nada; antes será fonte de riqueza e de desenvolvimento, em que a duração se fará no movimento e não no enraizamento.

Já se anunciam os primeiros princípios jurídicos dessa democracia sem fronteiras. Cada um de nós deveria ter o direito e o dever de ajudar na instauração da democracia e da dignidade humana em todos os lugares; cada um de nós deveria ter o direito de votar onde decidiu viver por algum tempo. Cada geração deveria prestar contas às gerações seguintes sobre seus próprios progressos, propiciando votarem as geraçóes passadas $\mathrm{e}$ as vindouras.

Dizendo em outras palavras, os estrangeiros, as geraçóes passadas e as gerações futuras têm o direito de voto no que eu chamaria de democracia sem fronteiras, sem fronteiras no tempo e no espaço. Uma democracia capaz de conservar, se diferencia - o que distingue - e de destruir o que se opóe - o que separa.

Nomadismo e liberdade constituem a grande aposta do futuro. É também, na minha opiniáo, o novo papel do político: conceber e ordenar essa nova arquitetura institucional, fixando direitos e deveres do nômade, sem, entretanto, inverter os papéis, fazendo do sedentário o novo bode expiatório.

Mais que em qualquer outro lugar, esses três princípios da Nova Ordem Mundial - santuário mundial, integração regional e nomadismo institucionalizado - aplicam-se e impóem-se de maneira imperiosa no Sul: o Sul precisa de integração regional. O Sul é um santuário mundial $e$, as suas culturas, filhas do deserto, procedem do nomadismo institucionalizado. 
O que é o Sul? Não é mais um conceito geográfico. Não há mais o Sul isolado do Norte. O Norte é em São Paulo. O Sul é em Los Angeles.

Constrangidos também pela história e pela geografia, encontramos o lugar de um terceiro momento necessário da História, de uma terceira descoberta, a da integraçáo regional do Norte e do Sul. Em 1492, a Europa riscou Jerusalém de seu mapa e descobriu as colônias. Até 1989, a Europa viveu as recaídas das contradiçôes dessa dominaçáo.

Devemos nos lembrar de 1492 porque essa redescoberta do Sul não deve ser acompanhar de novo gueroush, de divórcio. Em outros termos, ninguém deve ser expulso em nome de uma pureza discutível. Cada um tem seu lugar.

O que ocorre hoje entre o Leste e o Ocidente é também rico em ensinamentos: para instaurar entre o Norte e o Sul relaçóes equilibradas de igual para igual, há vias práticas, a exemplo das seguidas atualmente na Europa. Podem ser chamadas de reconhecimento mútuo, desarmamento, democracia e desenvolvimento econômico em toda a região. Exigem o surgimento de solidariedade entre esses dois tipos de nômades do mundo.

As pessoas do Norte e as do Sul, em uma mesma região, as que já existem e as que viráo, devem aprender a se descobrir, a cooperar, começando em nível relativamente modesto e, posteriormente, com a instauração da confiança, fixarem-se em objetivos mais ambiciosos.

Gostaria de tomar como exemplo uma regiáo particularmente simbólica, o Oriente Próximo. $O$ alinhamento progressivo das suas despesas militares em níveis mundiais permitiria liberar somas consideráveis de até 50 bilhóes de dólares por ano.

Em seguida, como no Leste Europeu, a colaboraçăo regional nos campos de interesse muituo, sobretudo na gestáo da água, saúde, telecomunicaçōes, transportes, agricultura, energia, turismo, beneficiaria a todos os países da regiáo e permitiria obtençáo de vantagens dessas complementaridades. Assim, os recursos de mão-de-obra tornar-se-iam verdadeiramente o complemento do capital e do savoir-faire técnico e profissional já existentes.

Outro objetivo a longo prazo seria a criação de zonas francas. Tanto no Oriente Médio, como ao redor do Mediterrâneo ocidental, poderiam ser chave para o desenvolvimento e a estabilizaçáo dos nomadismos que se prenunciam. 
Essa cooperação econômica favorecerá a passagem para a cooperaçáo cultural e política, e será a melhor garantia da paz.

Finalmente, a meu ver, para organizar tal cooperaçáo, seria importante criar rapidamente, no contexto das negociaçóes de paz atuais, instituiçóes regionais ligando Norte è Sul, como um Banco do Oriente Próximo (ou Mediterraneo) para a reconstrufáo e o desenvolvimento. Esse procedimento teria como objetivo a reconstruçáo das economias do Oriente Próximo, dilaceradas pela guerra, contribuindo para o desenvolvimento de infra-estrutura regional, como faz o Banco Europeu para a parte oriental da Europa. Financiaria a edificaçăo de instituiçóes democráticas, assim como o desenvolvimento do setor privado e de infra-estrutura que a ele conduzisse. Seria o fórum no interior do qual se abordariam outras questôes de interesse mútuo. Esse Banco do Oriente Próximo, se criado, poderia também gerir um Fundo especial de empréstimo para os países mais pobres da regiáo. Os Estados do Golfo, que têm seus próprios programas bilaterais de desenvolvimento, certamente dariam sua contribuição. Graças a esses fundos, os doadores poderiam ter certeza de sua ajuda ser adequadamente empregada; e, contando a direçáo do empreendimento com representantes dos países que emprestam e dos que tomam empréstimos, permitiria a canalização dessa ajuda coletiva mais eficaz e seguramente, se comparada a uma série de acordos bilaterais. Seria, enfim, o cinturăo natural, no qual aplanar-se-iam as dificuldades econômicas e políticas. $O$ mesmo pode ser imaginado para os países banhados pelo Mediterrâneo ocidental.

O início promissor do Banco Europeu, apenas um ano depois de sua criaçáo, indica de modo positivo o papel que poderia ser desempenhado por instituição semelhante no Oriente Próximo.

Os membros de fora poderiam organizar uma reuniăo de lançamento, para a qual convidariam todos os países da regiáo, bem como os demais interessados. Manifesto essa idéia, esperando que alguém a retome e a desenvolva.

$* * * * * *$

A barbárie é o mais provável. O político é uma rolha flutuando à deriva, na tempestade das paixões.

Cabe ao descobridor a responsabilidade pelo uso de sua descoberta. Assim, ele deve pensar antecipadamente no peso dessa responsabilidade. A descoberta não é inocente: tem o peso da verdade e o fardo da responsabilidade. Sempre foi um encontro no qual cada um deve fazer 
a sua parte, em que cada um é responsável pelo proporcionado a si mesmo, aos outros e ao mundo.

Descobrir é ir em direção ao outro com humildade. É lembrar que Adão era um nomade feito de argila; que o pecador, obrigado a deixar o jardim do Éden, era um descobridor, e os homens do deserto, para sobreviver, deveriam organizar, pelos ritos, a transmissaio de uma fé.

Para mim, nomadismo, descoberta e transmissáo constituem a trama entrelaçada da condiçáo humana. O nomadismo é descoberta. A descoberta é transmissáo. A transmissão é nomadismo. Ambos decidirâo se o amanhã será barbárie ou liberdade.

Jacques Attali é presidente do European Bank Reconstruction Development, com sede em Londres. Nasceu na Argélia, em 1943, e se graduou na École Polytechnique, École des Mines, Institut d'Études Politiques $\mathrm{c}$ Écolc Nationalc d'Administration. Fez doutorado em Ciências Econômicas. Em 1970, ingressou no "Conseil d'État", onde se tornou conselheiro em 1989. Entre maio de 1981 e abril de 1991, foi conselheiro especial do presidente da França, François Mitterrand. Escreveu 15 livros, incluindo romances e ensaios, além de roteiros de filmes.

Traduçāo de Helena P. C. Pereira e Rena Signer. O original em francês "Nomadisme et Liberté" - encontra-se à disposição do leitor no IEA para eventual consulta. 